Florida and the various installations for building rockets and assembling them which are scattered over much of the United States? And what is to happen to the astronauts? Are some of them to be made redundant without ever having left the ground? No doubt NASA has been hoping to find answers to some of these questions in the wave of speculation there has been about the ways in which people could help to make good use of extra-terrestrial telescopes and other scientific equipment launched into orbit about the Earth or elsewhere. The trouble, alas, is that there has emerged no compelling reason why people should be preferred to automatic instruments, at least when due account is taken of their relative cost and lack of endurance. If purely technological considerations were the only ones at stake, NASA would find itself with a much straitened budget for manned space flight in the early seventies-and would probably put more energy into the development of novel kinds of rocket propulsion instead.

Such a shift to predictably useful tasks is probably too much to hope for. Manned space flight is already a kind of industry in its own right, and it will be hard for the Administration to hold NASA to a strictly ascetic course. In the end, in 1968 and not in 1967, there will probably be a compromise of some kind, with more circuses than the purists would like but fewer than the enthusiasts have set their hearts on. In itself, that need do no harm, although it is important that everybody should recognize that the case for continuing more than a modest programme of manned space flight is not technological but economic. From this point of view, of course, what Congress will have to decide is not what NASA and its astronauts should do, but what the country and its taxpayers can afford. Keynesians in the Administration may think it ironical that a programme of development originally advocated as a kind of economic regulator to bring prosperity to an economy which showed signs of flagging in the early sixties, and to parts of the country which were especially depressed, should be hard to cut back to a reasonable size when the real danger is seen to be inflation, not slump. The long-term moral is, of course, that technological programmes like Apollo should stand or fall by their own merits, and not by external considerations, economic or political. It will be something gained if this lesson is now learned in the United States. It applies elsewhere as well, as the recent history of organizations such as ELDO has made quite clear.

\section{GOVERNMENT LABORATORIES}

There is great virtue in the steps which the British Government seems to be taking to forge closer links between its research laboratories and the universities. A number of patterns are being tried out by different governmert departments, and it will be interesting to see how successful they are in meeting the clear need for much easier interchange of people and ideas between the two kinds of establishments. It is not perhaps surprising that the most common form of interchange at present is the process whereby research students are allowed to work for a postgraduate degree at a public laboratory, and under the supervision of a civil servant, for research students are easily uprooted. (The University of Warwick, for one, has broken new ground by making such an arrangement with industrial research laboratories.) Another mechanism, typified by the arrangement now concluded between the Royal Aircraft Establishment and the University of Southampton, involves joint appointments of staff and the sharing of facilities in such a way that universities have access to equipment they would not otherwise be able to afford. A third, with which the Ministry of Overseas Development appears to be toying (see this issue, page 766), is the outright transfer of a research establishment to a university, presumably in such a way that the scientists concerned contribute fully to the teaching programme of the university. It is only natural that the question should arise of which way is best.

Enough is already known of the placing of research students in government laboratories for some of the advantages and disadvantages to be plain. Although such arrangements add to the stock of highly qualified people and thus to the national assets, there is a feeling that the government laboratories have the better half of their bargain with the universities. Sometimes it seems as if they take the cream off the crop of graduates without contributing to the hard teaching of the universities in return. Then it is possible that time spent in a government laboratory in isolation from a university is not the most educative way of winning a postgraduate degree; everything depends on the laboratory. Schemes which involve joint appointments are obviously an improvement, in that government scientists are drawn fully into the academic world, though it would be unfortunate if the result were to sanctify the view that universities should go begging to the establishments for really expensive equipment instead of owning it for themselves. Here, too, everything will depend on the establishment-and on the university-but the difficulties are potentially great enough to make the pattern in which the Ministry of Overseas Development is interested particularly attractive. By moving establishments physically and constitutionally to a university, the government can hope to increase their effectiveness in research and their contribution to teaching. It is true that there are not many establishments small and self-contained enough to be dealt with in this way, but if the Ministry of Overseas Development is successful in moving two of its laboratories to the University of Reading, there should be set in train a thorough search for other public laboratorics to be dealt with in the same way. There could hardly be a more effective way of inoculating the universities with the technological spirit. 